\title{
INVESTIGANDO A ESTRUTURA MORFOSSINTÁTICA DAS FORMAÇÕES EM DES-X-AR: UM ENFOQUE NO FENÔMENO DA PARASSÍNTESE
}

\author{
INVESTIGATING THE MORPHOSYNTACTIC STRUCTURE OF DES-X- \\ AR FORMATIONS IN BRAZILIAN PORTUGUESE: FOCUSING ON THE \\ PARASYNTHESIS PHENOMENON
}

\begin{abstract}
Paula Roberta Gabbai Armelin | Lattes | paula.rg.armelin@gmail.com Universidade Federal de Juiz de Fora
\end{abstract}

Nilton Duarte Melo | Lattes | niltonduartemelo@gmail.com Universidade Federal de Juiz de Fora | CAPES

Resumo: Este trabalho revisita a formação de verbos parassintéticos em $d e s$ - $X$-ar no português brasileiro, a partir de uma perspectiva sintática (HALLE; MARANTZ, 1993). A parassíntese caracteriza-se pela anexação simultânea de um sufixo e um prefixo a uma base, sendo que a ausência de algum desses elementos torna a construção agramatical (SAID ALI, 1966; CAMARA Jr., 1975; KEHDI, 2005; BASÍLIO, 2009). Trata-se de um processo interessante, pois parece desafiar a hipótese da ramificação binária. Descritivamente, propomos três padrões para as formações em des-X-ar: verbos não parassintéticos (desrespeitar); parcialmente parassintéticos (despentear) e totalmente parassintéticos (desossar). $\mathrm{Na}$ implementação da proposta desenvolvemos uma estrutura sintática estritamente binária, em que o prefixo des- pode aparecer em duas diferentes posições estruturais. Uma delas inclui a anexação do prefixo diretamente à raiz, o que tem como consequência o fato de o próprio prefixo integrar o processo de verbalização, entrando na estrutura antes do categorizador. Tal estrutura explica dados como desossar, por exemplo, em que, na ausência do prefixo, a formação se torna agramatical. Nessas estruturas, o prefixo em questão projeta seu rótulo na estrutura sintática. A segunda posição, por sua vez, é estruturalmente mais alta do que o núcleo categorizador e explica dados como despentear ou desrespeitar, por exemplo, em que, mesmo na ausência do prefixo, a formação é gramaticalmente possível. Nesses casos, o prefixo des- é considerado um adjunto, não alterando as propriedades formais da estrutura. Por fim, em ambas as estruturas, propomos que o argumento interno é inserido através do categorizador verbal.

Palavras-chave: Parassíntese; Circunfixação; Estrutura argumental; Localidade. Morfossintaxe. 
Abstract: This work revisits parasynthetic formations in des-X-ar in Brazilian Portuguese under a syntactic perspective (HALLE; MARANTZ, 1993). Parasynthesis is characterized by the simultaneous attaching of a suffix and a prefix to a base, and the absence of any of these elements renders the formation ungrammatical (SAID ALI, 1966; CAMARA JR., 1975; KEHDI, 2005; BASILIO, 2009). This is an interesting process, as it seems to challenge the binary branching hypothesis. Descriptively, we propose three patterns for the formations in des- $X$-ar: non-parasynthetic verbs, partially parasynthetic verbs and totally parasynthetic verbs. In the implementation of the proposal we developed a strictly binary syntactic structure, in which the prefix des- may appear in two different structural positions. One of them includes attaching the prefix directly to the root, which has as a consequence the fact that the prefix itself integrates the verbalization process, entering the structure before the categorizer. Such a structure explains the pattern in which the absence of the prefix correlates to ungrammaticality. In these structures, the prefix projects its label into the syntactic structure. The second position, in turn, is structurally higher than the categorizing head and it explains the patterns in which the absence of the prefix does no correlate to ungrammatically. In these cases, the prefix is considered to be an adjunct, since it does not change the formal properties of the structure. Finally, in both structures, we propose that the internal argument is inserted through the verbal categorizer.

Keywords: Parasynthesis; Circumfixation; Argument structure; Locality; Morphosyntax.

\section{Introdução}

A parassíntese é um processo de formação de palavras que se caracteriza, tradicionalmente, pela afixação simultânea de um prefixo e um sufixo a uma base (SAID ALI, 1966, CAMARA Jr., 1975; KEHDI, 2005; BASÍLIO, 2009, entre outros). Dentro dessa perspectiva, a ausência de um dos afixos torna a construção resultante agramatical na língua. No português brasileiro (PB), há uma variedade de formadores cuja anexação ao elemento de base é considerada pela tradição gramatical um processo parassintético, tal como pode ser visto abaixo (cf. RIO-TORTO, 2004): 
(1) Diferentes formadores parassintéticos no PB

a. $\quad a$-X-aragrupar*agrupo (nome) ${ }^{*}$ grupar

b. en-X-arenlatar*enlata (nome)* latar

c. es-X-aresvaziar* esvazio (nome)*vaziar

d. des-X-ardesossar* desosso (nome)*ossar

Assim, nos dados em (1a-d), a exclusão, seja do prefixo, seja do sufixo, resulta em uma formação inexistente no $\mathrm{PB}$, o que caracteriza a parassíntese.

Do ponto de vista da teoria linguística, a parassíntese é um processo interessante, pois a anexação simultânea de um sufixo e um prefixo a uma base parece, em princípio, desafiar a hipótese da ramificação binária (cf. CORREIA e ALMEIDA, 2012) comumente assumida na hierarquização dos elementos, seja no interior da sentença, seja no interior da palavra.

Inserido na área da Teoria da Gramática, mais especificamente no âmbito dos estudos a respeito da formação de palavras, este artigo pretende investigar as formações verbais parassintéticas construídas em des-X-ar, buscando propor uma estrutura morfossintática capaz de derivar as propriedades empíricas dessas formações e que, além disso, se mostre apropriada do ponto de vista teórico-explicativo. A hipótese de base que guia este artigo é a de que uma perspectiva sintática da formação de palavras é capaz de desfazer muitas das controvérsias que cercam o tema. Então, para implementar a proposta, apoiamo-nos na perspectiva teórica da Morfologia Distribuída, doravante MD (HALLE e MARANTZ, 1993; MARANTZ, 1997).

Como ponto de partida, elaboramos um corpus não exaustivo de referência através de uma coleta de dados feita na versão eletrônica do Dicionário Houaiss da Língua Portuguesa (2009). Mais especificamente, as formações parassintéticas construídas com a anexação de des- $X$-ar constituem um fenômeno linguístico bastante interessante por revelar padrões diferenciados de construção linguística, constituindo-se, portanto, como um campo bastante fértil para as pesquisas a respeito da formação de palavras no $P B$. Nesse sentido, três padrões diferentes de formações verbais em des- $X$-ar são propostos neste trabalho:

(2)

\begin{tabular}{|l|l|l|}
\hline & Ausência do elemento prefixal & Ausência do elemento sufixal \\
\hline a. descabelar & *cabelar & *descabelo (nome) \\
\hline b. despentear & pentear & *despente (nome) \\
\hline c. desrespeitar & respeitar & desrespeito (nome) \\
\hline
\end{tabular}


Denominamos as formações do tipo (2a) de parassíntese total, já que a ausência, seja do elemento prefixal, seja do elemento sufixal, tem como resultados dados agramaticais. Por outro lado, denominamos os casos como (2b) de parassíntese parcial, uma vez que, mesmo com a ausência do elemento que antecede a base, o resultado é uma formação gramatical. Por sua vez, o padrão em (2c) foi considerado não parassintético, porque a presença, seja do sufixo, seja do prefixo, é suficiente para gerar um dado existente na língua.

As formações em des-X-ar parecem apontar para uma estreita interação entre morfologia e sintaxe em decorrência das relações de estrutura argumental que são consequências da possibilidade ou da impossibilidade da ausência do prefixo, o que aponta para a possibilidade de implementar uma análise sintática de formação de palavras. A partir desse enfoque, propomos uma representação sintática estritamente binária em que o prefixo des- pode ocupar duas posições sintáticas diferentes.

Em formações totalmente parassintéticas: o prefixo anexa-se abaixo do núcleo categorizador verbal;

Em formações parcialmente e não parassintéticas: o prefixo anexa-se acima do núcleo categorizador verbal.

Além disso, assumimos que haja apenas um item de vocabulário (IV) para a realização desse prefixo, sendo que as diferenças entre os padrões propostos advêm, então, das diferentes posições que ele pode ocupar na estrutura sintática. Por fim, propomos que o processo verbalizador é, em si, responsável por abrir uma posição para a introdução do argumento interno na estrutura sintática dessas formações.

O presente trabalho está divido nas seguintes seções: na seção 2 , apresentamos as propriedades empíricas dos padrões encontrados na coleta dos dados. Na seção 3, fazemos uma breve discussão sobre os diferentes conceitos envolvidos na noção de parassíntese e de circunfixação. Na seção 4, apresentamos o modelo teórico e as motivações por trás da escolha de uma corrente teórica de formação sintática de palavras. Na seção 5, verificamos o que propostas anteriores apontam sobre as questões em estudo (VILLAVA, 1994; MEDEIROS, 2010, 2016; BASSANI, 2013). Na seção 6, apresentamos nossa proposta de derivação dos verbos em des-X-ar. Por fim, a seção 7 encerra o artigo com as considerações finais.

\section{Descrição dos dados e generalizações empíricas}

O nosso ponto de partida na investigação do fenômeno da parassíntese nas formas verbais em des- $X$-ar foi a formação de um corpus de referência construído a partir de uma 
coleta não exaustiva de dados encontrados na versão eletrônica do Dicionário Houaiss da Língua Portuguesa (2009). A coleta inicial retornou um total de 1352 verbetes iniciados por des- e terminados por -ar. Os dados foram submetidos a uma limpeza manual, na qual foram excluídos:

Dados que, apesar de dicionarizados, não figuravam como verbetes utilizados no cotidiano da fala do $\mathrm{PB}$, apresentando uma baixa ocorrência em busca online no Google, tais como: desabalroar, desacoimar, desencravilhar, desterneirar, desvizinhar.

Dados em que des- não se comporta efetivamente como prefixo, tal como em desfilar e despejar, por exemplo.

Mais especificamente, um total de 911 verbetes foram excluídos da análise. Para o restante dos verbetes, propusemos uma divisão descritiva em três classes distintas: verbos não parassintéticos, verbos parcialmente parassintéticos e verbos totalmente parassintéticos.

De maneira geral, a classe dos verbos não parassintéticos é caracterizada pelo fato de que a ausência, seja do prefixo, seja do sufixo, não gera agramaticalidade na formação, tal como se pode ver abaixo:

(3) a. desrespeitar - respeitar/ desrespeito

b. desacatar - acatar / desacato

c. desapegar- apegar/ desapego

d. desgastar - gastar/ desgaste

e. desgostar - gostar/desgosto

Por sua vez, o padrão parcialmente parassintético é caracterizado pelo fato de que a ausência de um dos afixos, normalmente do prefixo , não gera agramaticalidade. Nesse sentido, a formação do verbo correspondente é possível, mas a formação do nome não é licenciada na língua.

(4) a. desabitar - habitar/*desabito (nome)

b. desacelerar - acelerar/*desacelero (nome)

c. desabotoar - abotoar/*desaboto (nome)

d. desabrigar - abrigar $/{ }^{*}$ desabrigo (nome)

e. desconsiderar - considerar/ ${ }^{*}$ desconsidero (nome)

Por fim, os verbos totalmente parassintéticos constituem um padrão realizacional em que a ausência de qualquer um dos afixos gera agramaticalidade da formação, como os exemplos abaixo ilustram: 
(5) a. desbravar - *bravar $/{ }^{*}$ desbravo (nome)

b. descabelar $-{ }^{*}$ cabelar/ ${ }^{*}$ descabelo (nome)

c. desabrochar $-{ }^{*}$ abrochar $/{ }^{*}$ desabrocho (nome)

d. desossar - *ossar $/{ }^{*}$ desosso (nome)

e. desovar - ${ }^{*}$ ovar $/{ }^{*}$ desovo (nome)

Embora a pesquisa realizada nesse artigo tenha uma base teórico-dedutiva e não seja de natureza essencialmente quantitativa, é interessante ressaltar que, em termos numéricos, a formação do corpus de referência retornou os seguintes resultados: 53 verbetes totalmente parassintéticos, 51 não parassintéticos e 337 parcialmente parassintéticos. Dessa maneira, a classe dos parcialmente parassintéticos mostrou-se como a mais produtiva. Por sua vez, os verbos totalmente e não parassintéticos tiveram um resultado aproximado na classificação final dos dados. Uma vez terminada a etapa de coleta, limpeza e organização dos dados, passamos à sistematização das propriedades dos padrões encontrados. É importante ressaltar que a formação do corpus de referência com a seleção dos itens de análise serviu como base para a descrição das propriedades empíricas dos dados. Tais propriedades, por sua vez, embasaram a proposta formalizada de estruturação sintática desenvolvida na seção 6 .

\subsection{Localidade morfofonológica entre o prefixo des- e a raiz}

$\mathrm{Na}$ computação das relações de localidade estamos considerando a (im)possibilidade de realização fonológica de um afixo intervindo entre des- e a raiz. Tais relações locais fornecem pistas importantes a respeito das relações hierárquicas estabelecidas pelos elementos na construção da estrutura sintática.

Nesse sentido, para os verbos totalmente parassintéticos, não foi encontrada qualquer evidência de que possa haver interveniência de um afixo entre des- e a raiz. $O$ padrão oposto, no entanto, é encontrado nos verbos parcialmente parassintéticos e não parassintéticos, nos quais, por sua vez, é possível haver um afixo intervindo entre des- e a raiz, tal como se pode ver na realização dos prefixos $-a$ - e -en- abaixo:

(5) a. Verbos parcialmente parassintéticos: desagrupar, desenraizar, desencorajar

b. Verbos não parassintéticos: desembarcar, desembolsar, desencantar

Essas relações de localidade parecem apontar, então, que a posição do prefixo des-é diferente nos dois casos acima, agrupando, de um lado, os verbos totalmente parassintéticos e, de outro, os verbos parcialmente parassintéticos e não parassintéticos. No primeiro 
caso, o prefixo deve ser hierarquicamente baixo na estrutura sintática, enquanto no segundo caso, tal elemento parece estar hierarquicamente mais alto. As posições sintáticas relevantes serão discutidas e definidas na seção de análise.

\subsection{Interação com a estrutura argumental}

A estrutura argumental, que diz respeito à organização de um predicado e dos argumentos que ele é capaz de selecionar, tem sido um tópico de destaque na tradição gerativista (cf. MARANTZ, 2013).

Especificamente com relação às formações em des- $X$-ar analisadas neste trabalho, os três padrões propostos caracterizam-se essencialmente por licenciar a entrada de um argumento interno. O licenciamento desse argumento na estrutura sintática é, portanto, um fato bastante relevante na análise dessas formações.

É interessante ressaltar, no entanto, que a relação entre os diferentes padrões empíricos e a presença do argumento interno apresenta algumas diferenças relevantes que parecem evidenciar uma estreita relação entre morfologia e estrutura argumental, ou mais precisamente, entre morfologia e sintaxe. Assim, nos verbos não parassintéticos e nos verbos parcialmente parassintéticos, o prefixo não parece ser exigido para que o argumento interno seja licenciado.

(6) a. Maria respeita os avós o tempo inteiro.

b. Mario desrespeita os avós o tempo inteiro.

(7) a. Lúcia penteou os cabelos antes de dormir

b. Lúcia despenteou os cabelos antes de dormir.

Nas sentenças acima, a presença do argumento interno os avós e os cabelos é independente da presença do prefixo. Dessa mesma forma, o estabelecimento de uma categorial verbal também é independente da presença do prefixo. Ainda é interessante notar que a entrada do afixo des- não desencadeia qualquer alteração nas propriedades formais do elemento a que ele se anexa.

Por outro lado, nos verbos totalmente parassintéticos, encontramos o cenário oposto. Assim, apesar de esses verbos também possuírem um argumento interno, tal elemento só é licenciado na presença do prefixo, que parece, efetivamente, ser um elemento relevante para a construção do predicado verbal.

(8) a. *ossar o frango.

b. desossar o frango 


\section{c. *tronar o regente \\ d. destronar o regente}

Como se pode ver nas formações acima, a presença dos argumentos internos o frango e o regente está totalmente atrelada à presença do prefixo que integra a formação verbal. A relação entre o prefixo des- e o licenciamento do argumento interno precisa ser captada, então, por uma análise que se debruça nesse tipo de dado.

\subsection{Composicionalidade da interpretação}

As formações em des- $X$-ar fomentam um interessante debate a respeito da interface com o componente de computação semântica da gramática, uma vez que nem todas as formações em questão apresentam interpretação composicional.

Em linhas gerais, considera-se que um sentido é composicional quando os significados das partes podem ser identificados no significado do todo. Em uma estrutura hierárquica ramificada, para que o sentido da formação seja composicional, cada nó sintático deve ser interpretado separadamente. Por outro lado, uma interpretação é considerada não composicional quando a soma do significado das partes não pode ser identificada no significado do todo.

É interessante ressaltar que são encontradas leituras composicionais e não composicionais em todos os diferentes padrões de formações em des- $X$-ar. As abordagens sintáticas de formação de palavras têm focado em delimitar um domínio sintático bem definido dentro do qual a interpretação não composicional poderia ser licenciada. Dentro dessa perspectiva, diferentes propostas para a computação do significado não composicional podem ser encontradas na literatura (cf. MARANTZ, 2001; 2007; 2013; ARAD, 2003; BORER, 2013a, 2013b, 2014). Nesse sentido, no que diz respeito às formações em des- $X$-ar, de maneira geral, interpretações composicionais e não composicionais foram licenciadas em todos os padrões:

(9) a. Totalmente parassintéticos composicionais: descafeinar, descarnar, desgalhar, desnatar, desossar;

b. Totalmente parassintéticos não composicionais: desabar, desbravar, descabelar, desmiolar, despontar.

c. Parcialmente parassintéticos composicionais: desacorrentar, desdobrar, desenroscar e desvalorizar;

d. Parcialmente parassintéticos não composicionais: desaforar, desandar, desapontar, desconcertar, deslumbrar. 
e. Não parassintéticos composicionais: desbloquear, desembaraçar, desencaixar, desencontrar, desjejuar;

f. Não parassintéticos não composicionais: desabafar, descontar, desempenhar, desesperar, desmanchar.

É interessante ressaltar que os verbos totalmente parassintéticos coletados para este trabalho apresentaram majoritariamente a semântica não composicional, com poucos casos de interpretação totalmente composicional. Por outro lado, o padrão contrário foi encontrado para a interpretação dos verbos parcialmente e não parassintéticos, que apresentaram poucos casos de não composicionalidade.

\subsection{Generalizações}

A partir das propriedades descritas nestas subseções, de modo geral, podemos resumir as generalizações nos seguintes pontos:

Nos verbos parcialmente parassintéticos e não parassintéticos pode haver a interveniência de um afixo entre des- e a raiz. Nos verbos totalmente parassintéticos, por sua vez, a presença de afixos entre des- e a raiz não é possível.

O licenciamento do argumento interno é verificado nos três padrões propostos.

Para os verbos parcialmente parassintéticos e não parassintéticos a presença do prefixo não parece ser fundamental para a introdução do argumento interno. Nos verbos totalmente parassintéticos, por outro lado, a ausência do prefixo parece integrar a formação do predicado verbal sendo, consequentemente, essencial para a entrada do argumento interno.

Em todos os padrões foram encontradas ocorrências de formações composicionais e não composicionais. Porém, os verbos totalmente parassintéticos apresentaram, majoritariamente, formações não composicionais e os verbos parcialmente parassintéticos e não parassintéticos apresentaram, majoritariamente, formações composicionais.

\section{Delimitando o fenômeno: parassíntese vs. circunfixação}

A definição de parassíntese como um processo de anexação simultânea de dois afixos a uma base parece, em princípio, desafiar a hipótese da ramificação binária. Para resolver esse impasse, alguns autores propõem tratar os dados em questão não como parassíntese propriamente dita, mas sim como um processo de circunfixação (LOPES, 2003; SILVA e KOCH, 2005; HENRIQUES, 2007).

A circunfixação se caracteriza pela anexação de um morfema descontínuo a uma 
base. Não se trata, portanto, da presença simultânea de dois elementos, um prefixo e um sufixo, mas de um único morfema, que se separa pela intercalação da base. A análise de circunfixação apresenta, porém, alguns problemas tanto teóricos quanto empíricos.

Um deles diz respeito ao fato de que o elemento que antecede a base e o elemento que precede a base podem ser morfologicamente independentes um do outro, exercendo, portanto, funções sintáticas e semânticas que, além de serem diferentes, podem ser facilmente atreladas a um ou outro elemento. Tal fato fica bastante evidente nas formações em des-X-ar.

(10) Semântica das formações parassintéticas em des-X-ar

a. destronar* destrono (nome) *tronar semântica: ação/processo de tirar do trono

b. descascar* descasca (nome) * cascar semântica: ação/processo de tirar a casca

c. desossar* desosso (nome) *ossar semântica: ação/processo de tirar o osso

Nos dados em (10a-c), por exemplo, é possível detectar que des-, o elemento que antecede a base, é especificamente responsável pelo sentido de negação, que permanece presente em todos os exemplos. Por outro lado, -ar, o elemento que segue a base, é responsável por evidenciar a categoria verbal da formação. Essa independência entre prefixo e sufixo não é esperada dentro de uma proposta de circunfixação, o que constitui um problema empírico.

Nesse sentido, assumir a existência de um afixo descontínuo des...ar resulta em um sistema redundante, visto que tanto des- quanto -ar aparecem como afixos independentes na língua e, empiricamente, tais afixos independentes comportam-se de forma muito semelhante às partes do suposto afixo descontínuo.

\section{Modelo teórico: do lexicalismo à sintaxe}

A morfologia caracteriza-se nos estudos linguísticos como a área da ciência que estuda as estruturas e os processos de formação das palavras. A partir dessa intuição, muitas correntes teóricas propuseram um contraste entre os processos de formação de palavras e de formação das sentenças (LIEBER, 1980; 1992; BASÍLIO, 1980, 2004; ARONOFF, 1976; entre outros). Dentre essas abordagens, encontram-se as teorias lexicalistas, que se caracterizam por considerar que há processos de formação de palavras que se dão dentro do léxico. Tais teorias subdividem-se em duas vertentes, conhecidas como Lexicalismo Forte e Lexicalismo Fraco.

No Lexicalismo Forte (ANDERSON,1992), todos os processos de formação de palavras, incluindo, portanto, os flexionais e os derivacionais, ocorrem no componente 
lexical. Nessa perspectiva, a sintaxe opera, então, com palavras prontas. Por outro lado, no Lexicalismo Fraco (CHOMSKY, 1970), as formações de palavras advindas dos processos de derivação são formadas no léxico, enquanto a flexão é formada na sintaxe. Essa divisão dá-se diante da ideia de que a flexão, mas não a derivação, seria relevante para a sintaxe, desencadeando, por exemplo, relações de concordância necessárias para a boa formação de sentenças.

De forma geral, as correntes lexicalistas, em suas duas vertentes, assumem um léxico bastante recheado de especificações de variadas ordens, tais como especificações semânticas, morfológicas, fonológicas e sintáticas, além do próprio rótulo categorial. Diante dessa quantidade de informação, a sintaxe passa a ser vista como um componente organizador de propriedades que já estão especificadas previamente no componente lexical.

Em oposição ao Lexicalismo, surgem, a partir dos anos 1990, correntes teóricas que assumem que a formação de palavras não apenas compartilha dos mesmos processos da formação de sentenças, como ocorre em conjunto à formação destas, no componente sintático. Nesse sentido, o único componente gerador de estrutura hierárquica passa a ser a sintaxe. Uma dessas correntes sintáticas de formação de palavras ficou conhecida como Morfologia Distribuída, doravante MD, (HALLE; MARANTZ, 1993; MARANTZ, 1997; e trabalhos subsequentes). A MD, em oposição às correntes Lexicalistas, trata a formação de palavras como produto da sintaxe. Nesse mesmo sentido, a MD propõe um esvaziamento do chamado componente lexical, sendo que as informações contidas no léxico passam a ser distribuídas em listas que ocupam diferentes posições na arquitetura da gramática. A esquematização do modelo de gramática proposto pela $\mathrm{MD}$ pode ser vista na figura (1) abaixo. Ao longo desse modelo de gramática, a MD propõe a existências de três listas:

Lista 1: contém os primitivos linguísticos com os quais a sintaxe opera, tal como núcleos funcionais, raízes, e traços morfossintáticos.

Lista 2: contém os chamados Itens de Vocabulário (IVs), que correspondem a associações entre o conteúdo fonológico e o contexto de inserção das peças disponíveis na língua. Configura-se, portanto, como uma relação entre fonologia e um conjunto de traços abstratos.

Lista 3: contém o conteúdo extralinguístico, ou seja, aquele conteúdo ligado às experiências de mundo do falante e não especificamente ao sistema linguístico 


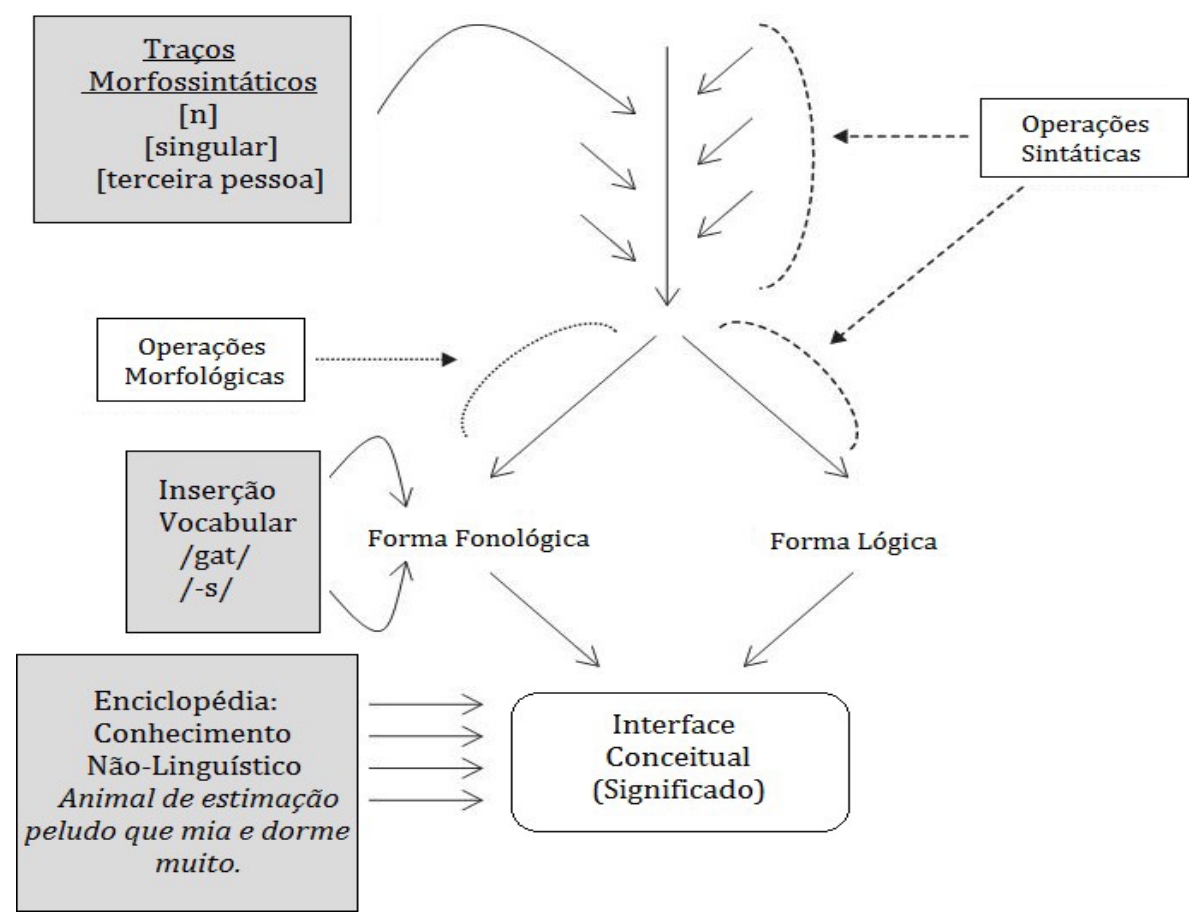

Figura 1. Modelo de gramática da Morfologia Distribuída (adaptada de SIDDIQI, 2009, p.14).

Na construção da derivação, a sintaxe opera com os elementos que estão contidos na Lista 1. Entre esses elementos estão os núcleos categorizadores, como $n$ (nome), $v$ (verbo), $a$ (adjetivo), que têm a função de fornecer categoria às raízes, uma vez que essas são destituídas de categoria gramatical. O componente sintático, por meio de operações, tais como merge (concatenar) e move (mover), organiza os elementos retirados da Lista 1 em uma estrutura hierárquica. Essa estrutura é, então, enviada para a PF (Phonological Form) e LF (Logical Form), níveis linguísticos em que serão computadas as informações fonológicas e lógicas, respectivamente. Mais especificamente acerca do trajeto feito entre o componente sintático e PF, vale ressaltar que, no ramo de PF, podem ocorrer as chamadas operações morfológicas, responsáveis por promover pequenos ajustes na estrutura gerada pela sintaxe. Por fim, as estruturas resultantes são acessadas pela Lista 3, nível em que as peças são associadas ao conteúdo extralinguístico.

Três propriedades importantes diferenciam o modelo da MD de outros modelos teóricos: a Inserção Tardia, a Subespecificação e a estrutura sintática por toda a derivação. A Inserção Tardia (Late Insertion) caracteriza-se pelo fato de que os elementos com os quais a sintaxe opera são desprovidos de conteúdo fonológico. Assim, a inserção de fonologia acontece depois da sintaxe, no braço de PF. Já a subespecificação, por sua vez, diz respeito à noção de que não é necessário que haja uma completa correspondência 
entre os traços do IV, que está contido na Lista 2, e os traços presentes nos nós terminais da estrutura sintática. Mais especificamente, o IV pode conter apenas um subconjunto de traços presentes no núcleo sintático. A inserção dos IVs é regida pelo Princípio do Subconjunto (HALLE, 1997). Esse princípio baseia-se na ideia de que há uma competição entre os IVs, sendo que apenas aqueles que não contêm traços conflitantes com os traços do núcleo sintático são elegíveis para serem inseridos. Por sua vez, o IV que contiver mais traços compatíveis com os traços de determinado núcleo sintático ganha a competição. Por fim, a estrutura sintática por toda a derivação consiste na hipótese de que a formação de palavras é estritamente sintática e, por isso, tanto a formação de palavras quanto a formação de sentenças ocorrem através dos mesmos processos e no mesmo componente da gramática.

Neste trabalho desenvolvemos uma proposta de análise a partir da perspectiva teórica proposta pelo modelo da MD. Tal modelo parece uma alternativa interessante de análise, uma vez que os dados apontam uma estreita relação entre morfologia e sintaxe, especialmente no que diz respeito à estrutura argumental e ao local de anexação do prefixo des-. Dados como (7) e (8) parecem evidenciar a possibilidade de que o argumento interno esteja presente na estrutura antes mesmo da entrada do prefixo des- no que diz respeito aos verbos parcialmente e não parassintéticos. Tal fato pode ser analisado como uma interação entre morfologia e sintaxe, se assumirmos que a entrada do argumento interno pode ocorrer intercalado ao processo de formação de palavra, que, por sua vez, pode não estar totalmente concluído.

Por outro lado, nos verbos totalmente parassintéticos, o prefixo des- parece integrar a formação verbal, sendo, portanto, a sua presença necessária para o licenciamento do argumento interno. Se esse raciocínio está no caminho correto, então, o modelo de gramática adequado deve permitir uma interação entre formação de palavra e estrutura argumental. Nesse sentido, a MD é um quadro no qual tal interação não só é permitida, como também é prevista pelo modelo de gramática. Já nas correntes lexicalistas, esse tipo de fenômeno não pode acontecer, uma vez que a formação de palavras está associada ao componente lexical.

Portanto, ao considerar que palavras são sintaticamente formadas, a MD permite o desenvolvimento de análises em que um mesmo elemento pode ocupar diferentes lugares na estrutura sintática. Dessa forma, ao local em que um elemento se anexa estão atreladas consequências sintáticas e semânticas importantes. Será, então, relevante para a análise desenvolvida neste trabalho o fato de que des- parece poder ocupar diferentes 
posições na estrutura sintática, sendo essas diferentes posições importantes para explicar o comportamento do prefixo nos diferentes padrões encontrados neste trabalho.

Além disso, o estatuto acategorial das raízes, bem como a ideia de que a categoria é um produto da relação entre raiz e estrutura sintática, parece ser interessante para explicar dados nos quais não há uma categoria diretamente associada à formação anteriormente ao processo de parassíntese, tal como em como deslocar e desvirtuar, por exemplo.

\section{0 fenômeno da parassíntese em análises anteriores}

Nesta seção apresentamos propostas anteriores que se debruçam sobre o fenômeno da parassíntese, atentando especificamente para as construções que envolvem o prefixo des-. Mais especificamente, partiremos de Villava (1994) em sua proposta sobre a configuração estrutural das palavras. Em seguida, analisaremos as propostas de Medeiros (2010, 2016) acerca do prefixo des- e, por fim, consideraremos a proposta de Bassani (2013) sobre os verbos parassintéticos. Alguns dos aspectos centrais dessas propostas serão discutidos e contrastados com a análise que desenvolvemos na seção 6 .

\subsection{Villalva (1994): parassíntese como conversão}

Villalva (1994) trata de alguns processos de formação de palavras, tal como a parassíntese, que parecem, em um primeiro momento, desafiar a hipótese da ramificação binária. A partir de uma proposta teórica própria denominada XM-Barra, a autora apresenta uma estrutura em que há dois níveis de operações: o mais baixo corresponde às operações morfológicas, enquanto o mais alto diz respeito às operações sintáticas.

Especificamente acerca dos verbos parassintéticos, Villalva (1994) analisa diferentes tipos de ocorrência desse fenômeno, dividindo-os em diferentes grupos. Um deles inclui as formações em que não há a realização de um sufixo derivacional, como em (11).
a. acampar
b. destronar
c. embarcar

A autora propõe que a formação desses verbos inclui um processo de conversão, em que um radical previamente categorizado passa a figurar como nova categoria gramatical sem que haja qualquer modificação morfológica que acompanhe essa alteração de categoria. A estrutura que representa esse tipo de formação pode ser vista abaixo ${ }^{1}$ :

\footnotetext{
${ }^{1} \mathrm{Na}$ estrutura (12), que traz a proposta de Vilalva (1994), as abreviações correspondem aos seguintes significados: RN para radical nominal; RV para radical verbal; VT para vogal temática; TV para tema verbal; FM para flexão morfológica.
} 
(12)

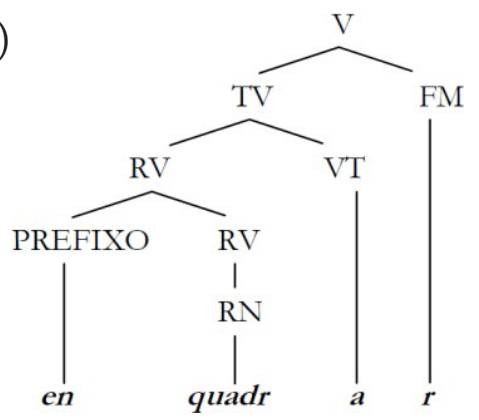

(VILLALVA, 1994, p. 7)

Note que, na formação acima, há um processo de conversão morfológica que altera a categoria do radical nominal para radical verbal antes mesmo da anexação do prefixo. É interessante observar ainda que, na proposta da autora, a entrada do prefixo é anterior à entrada da vogal temática. ${ }^{2}$

Villalva (1994) reconhece também a existência de formações parassintéticas que são construídas a partir de um sufixo derivacional fonologicamente realizado, como em (13) abaixo:

(2) (13) a. escurecer

(3) b. pestanejar

(4) c. pentear

A estrutura proposta em Vilalva (1994) para dar conta dessas formações é a seguin$t^{3}$ :

(14)

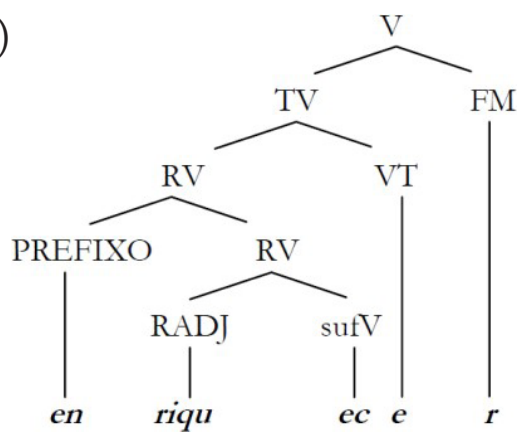

(VILLALVA, 1994, p. 7)

Na estrutura acima, o processo de conversão não acontece. Existe, na verdade, um

\footnotetext{
${ }^{2}$ Um parecerista anônimo questionou se o fato de a entrada do prefixo ser anterior à entrada da vogal temática poderia ser problemático, tendo em vista a existência do verbo "quadrar", muito vivo em português europeu. Acreditamos, no entanto, que, no sistema da autora, a existência do verbo em questão não é problemática, uma vez que ela assume que o radical nominal se converte em radical verbal antes da entrada do prefixo. Ressaltamos, no entanto, que a natureza do processo de conversão entre radicais categorizados é um ponto que precisa ser discutido. Neste trabalho, abandonamos esse processo de conversão em favor da noção de raízes acategoriais, que só podem ser categorizadas em um contexto sintático adequado.

${ }^{3} \mathrm{Na}$ estrutura (14), que traz a proposta de Vilalva (1994), as abreviações correspondem aos seguintes significados: RADJ para radical adjetival; SufV para sufixo verbal; RV para radical verbal; VT para vogal temática; TV para tema verbal; FM para flexão morfológica.
} 
radical adjetival, ao qual se junta um sufixo derivacional. Essa junção, por sua vez, tem como resultado a formação de um radical verbal. É importante notar que a entrada do sufixo é anterior à entrada do próprio prefixo, o que parece indicar que há a formação de um verbo antes mesmo da prefixação.

De maneira geral, podemos dizer que Villalva (1994), em sua análise que engloba os verbos parassintéticos, propõe que, na ausência de um sufixo derivacional verbalizador, a mudança de categoria dos radicais se dá por meio do processo de conversão. Por outro lado, havendo a presença de um sufixo derivacional, tal elemento passa a ser responsável pela mudança categorial do radical. Por fim, vale ressaltar o fato de que, em ambos os casos, a mudança categorial do radical ocorre antes da entrada do prefixo.

\subsection{Medeiros (2010, 2016): uma única altura para o prefixo -des}

Medeiros $(2010,2016)$ desenvolve uma análise para o prefixo des- dentro dos moldes da MD. Na primeira das propostas, Medeiros (2010) considera que o prefixo des- não faz seleção categorial, mas sim uma seleção semântica, contrariando a proposta de Silva e Mioto (2009). ${ }^{4}$ Essa seleção semântica, proposta pelo autor, está ancorada na hipótese de que o prefixo em questão seleciona elementos, sejam raízes ou formações já categorizadas, que denotam estado, sendo que a função do prefixo é exatamente negar tal estado pressuposto.

A implementação da proposta de Medeiros inclui a ideia de que o prefixo des- é, portanto, a realização de um núcleo funcional NEG. Em termos formais de análise o autor apresenta seguinte estrutura: ${ }^{5}$

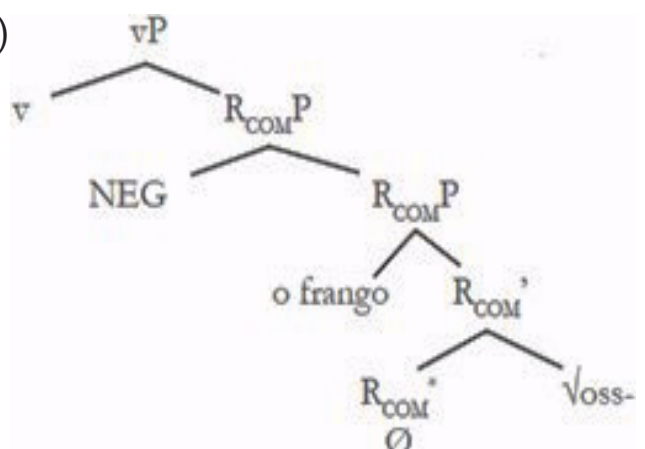

(Adaptado de MEDEIROS, 2010, p. 113)

\footnotetext{
${ }^{4}$ Em linhas gerais, Silva e Mioto (2009) propõem que o processo de prefixação tem uma natureza muito semelhante ao processo de sufixação, sendo, portanto, o prefixo responsável por selecionar categorialmente a sua base de anexação.

${ }^{5}$ Um parecerista anônimo questionou a respeito do percurso da estrutura sintática à estrutura morfológica. Assumimos que tal percurso é dado através das propriedades tradicionais de movimento de núcleo, que é uma operação estritamente local.
} 
$\mathrm{Na}$ estrutura acima, que se refere a "desossar o frango", o autor propõe, como Bassani, Medeiros e Scher (2009) e Bassani (2013), que um núcleo relacionador (R), representado por uma preposição abstrata "com”, se concatena à raiz e é o responsável pela relação entre a raiz e o argumento interno, sendo também o responsável pela introdução do mesmo na estrutura. Além disso, R projeta seu rótulo até a entrada do núcleo $v$. O núcleo NEG, local da realização fonológica de des-, é formalmente um adjunto, já que não é capaz de projetar um rótulo na estrutura sintática. A altura do núcleo NEG, acima do argumento interno, permite que a função de negação do prefixo tenha escopo sobre toda a estrutura abaixo de $v$. Assim, o autor assume, nessa proposta, que des- não se concatena diretamente à raiz e que o local de realização desse prefixo é alto na estrutura.

Em uma reanálise de sua proposta, Medeiros (2016) desenvolve uma abordagem em que o introdutor do argumento interno é um sintagma raiz $(\sqrt{\mathrm{P}})$, sendo que des- se adjunge diretamente a esse sintagma, tal como pode ser visto na estrutura abaixo, que representa uma formação hierárquica sem a realização fonológica dos núcleos e do sintagma raiz:

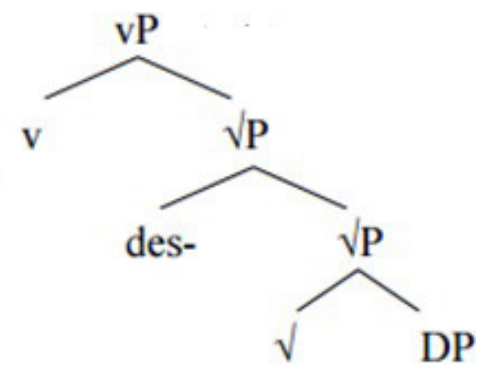

(Adaptado de MEDEIROS, 2016, p. 67)

Na estrutura acima, nota-se que o argumento interno é selecionado pela própria raiz, que projeta o seu rótulo na estrutura sintática. O prefixo é, então, introduzido na estrutura como um adjunto sob o escopo de $\sqrt{ } P$. Somente após a introdução do prefixo é que o núcleo verbalizador $v$ é anexado à estrutura. Esse núcleo cumpre a função de conferir categoria verbal à formação e é o local de realização dos sufixos verbalizadores, quando houver a ocorrência desses.

É interessante ressaltar a caracterização do prefixo em análise como uma espécie de modificador adverbial. A escolha por essa definição se baseia na ideia de que o prefixo em questão não modifica as propriedades formais, tal como a categoria, por exemplo, da estrutura a que ele se anexa. Segundo o autor, se o prefixo fosse considerado como a realização de núcleos categorizadores isso geraria uma redundância dos elementos no Léxico Estrito, Lista 1, ou uma maior especificação do feixe de traços desses núcleos. Além disso, 
se considerado como núcleo categorizador, a depender da altura em que esse núcleo seria anexado à estrutura, alguns problemas poderiam surgir acerca da categoria final desses constituintes. Considerar des- como modificador adverbial (e adjunto) evitaria possíveis problemas gerados por fatores de categorização.

Além disso, para Medeiros (2016), o fato de des- estar mais local à $\sqrt{ } P$ faz que, no momento da ordenação dos núcleos, via movimento, des- esteja mais próximo da raiz, uma vez que o autor considera que os movimentos de núcleos se estendem também a núcleos adjuntos. A estrutura explica também o porquê do argumento externo não estar dentro do escopo de des-, visto que ele é inserido na estrutura via Voice e o prefixo é inserido na estrutura abaixo de Voice.

Ainda sobre Medeiros (2016), uma estrutura como em (16) pode explicar também o fato de particípios que contêm o prefixo des- denotarem estado-alvo, ou seja um estado atingido pelo argumento interno. Segundo o autor, a possibilidade de alguns particípios denotarem estado-alvo, como os que contêm o prefixo des-, pode ser explicada: 1) pela inserção de um núcleo (morfema) aspectual, em que a raiz tem leitura de estado, diretamente ao sintagma raiz; ou 2) acima de $v P$ em que o verbalizador seria realizado por um alossema não eventivo de $v$ (de alguma maneira isso explica a presença de vogal temática nos particípios), dessa forma mesmo particípios com sufixos verbalizadores como -izpodem denotar estado-alvo. $\mathrm{O}$ autor ainda considera que, na sintaxe visível ou encoberta, o complemento deve se mover para fora do $v \mathrm{P}^{6} \mathrm{e}$, dessa forma, a estrutura proposta também explicaria a razão da quantificação do complemento ter escopo sobre o prefixo.

É possível explicar também, segundo o autor, a razão de des- poder se anexar a nomes e adjetivos não derivados de verbos, visto que o prefixo não faz nenhum tipo de seleção categorial, sendo necessário que haja apenas uma compatibilidade semântica entre prefixo e base. Por fim, Medeiros argumenta em favor da impossibilidade do prefixo ter escopo sobre advérbios visto que estes devem anexar-se acima de VoiceP, ou seja, em camadas muito acima das camadas ocupadas por des-.

\subsection{Bassani (2013)}

Bassani (2013) analisa, também através dos pressupostos teóricos da $\mathrm{MD}$, a estrutura morfossintática de verbos parassintéticos do PB iniciados pelos prefixos $a$, en- e es-. Em sua análise, a autora apresenta a proposta de que tais prefixos são a realização fonológica de um núcleo relacionador $(\mathrm{R})$, responsável pela introdução do argumento interno dos verbos parassintéticos.

\footnotetext{
${ }^{6}$ Baseado em Chomsky 1995, Medeiros (2016) assume esse movimento para checagem de Caso.
} 
Em linhas gerais, Bassani (2013) propõe que a estrutura dos verbos parassintéticos deve conter, obrigatoriamente, pelo menos quatro núcleos: $\sqrt{ }$ raiz, $R$, ve Th, tal como se pode ver abaixo:

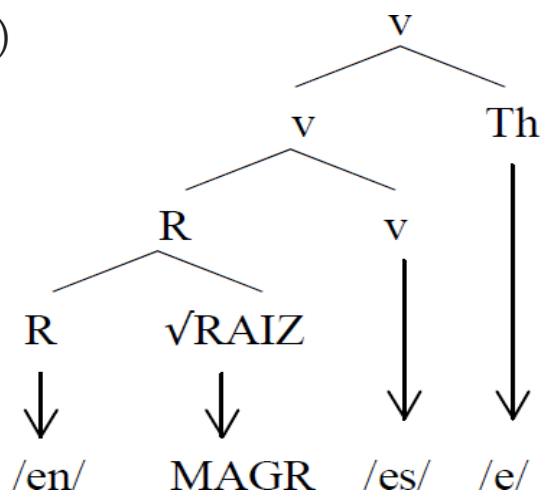

(BASSANI, 2013, p. 235)

O núcleo $\mathrm{R}$ concatena-se diretamente à raiz, sendo o local de realização fonológica do prefixo. Tal núcleo é responsável ainda por estabelecer uma relação entre a raiz e o argumento interno. Após a concatenação entre $\mathrm{R}$ e raiz, ocorre a entrada no núcleo $v$, momento a partir do qual a estrutura recebe categoria gramatical. O núcleo Th, lugar de realização da vogal temática, é inserido pós-sintaticamente através de uma operação morfológica nos termos de Oltra-Massuet (1999). ${ }^{7}$ É interessante ressaltar que Bassani (2013) propõe ser o núcleo R o responsável pela introdução do argumento interno. Uma justificativa utilizada pela autora para tal proposta é a agramaticalidade das formações parassintéticas em que o prefixo está ausente.

Em termos da especificação do núcleo $\mathrm{R}$, a autora propõe a existência de um traço relacionador $[+r]$, sendo que as suas diferentes realizações fonológicas se dão a partir de uma negociação feita entre a raiz e o próprio núcleo R. Para os verbos de mudança de estado, de posse abstrata e de configuração de $v$, $\mathrm{R}$ tem apenas o traço [+r]. Já para os verbos de mudança de posse concreta, $\mathrm{R}$ tem os traços $[+\mathrm{r}]$ e $[+$ dir $]$. Por fim, para os verbos de mudança de lugar, $\mathrm{R}$ é o mais especificado contendo os traços [+r], [+dir] e [+dentro] ou [+fora] ou [+próx]. No momento da inserção dos IVs, há uma competição para que o elemento que mais se aproxima dos traços especificados preencha fonologicamente o núcleo R.

Ainda sobre o núcleo $\mathrm{R}$, a autora ressalta que esse núcleo não é cíclico, ou seja, não desencadeia uma fase, sendo que o verbo e seu argumento interno só sofrem spell-out

\footnotetext{
${ }^{7}$ Para alguns autores, a vogal temática é considerada um requerimento de boa formação morfológica sem qualquer impacto de natureza sintática. Para uma argumentação a respeito da natureza pós-sintática da vogal temática, remetemos o leitor a Oltra-Massuet (1999) para o catalão, Harris (1999) para o espanhol e Alcântara (2003) para o PB.
} 
após a entrada de $v$, que tem, por sua vez, o estatuto de núcleo de fase. A autora assume que $\mathrm{R}$ não é um núcleo de fase, pois a raiz e o prefixo não têm independência fonológica, porém apresentam independência de significado.

Para reforçar sua proposta a autora aponta para o fato de que a raiz se anexa diretamente ao prefixo, não podendo haver nenhum elemento entre o prefixo e a raiz, ou seja, há uma relação de localidade entre esses dois elementos e as restrições fonológicas que há entre o fim do prefixo e o início da raiz demonstram essa relação de proximidade.

A autora argumenta ainda em favor da ocorrência do núcleo $\mathrm{R}$ também em verbos não prefixados. Uma evidência em favor dessa análise seriam os exemplos de variação diacrônica do português, tal como verbos que, em algum momento do desenvolvimento do português, já foram prefixados: alimpar $\rightarrow$ limpar. Outra evidência apresentada é a de que, em algumas línguas como o russo e o inglês, por exemplo, alguns prefixos têm poder de modificar a grade argumental dos verbos.

Acerca da discussão existente na literatura entre as possíveis análises do fenômeno em questão como parassíntese ou circunfixação, Bassani, rebatendo Rio- Torto (2004) e Pereira (2007), faz a seguinte afirmação:

A suposta dependência prefixo-sufixo nos verbos parassintéticos é um epifenômeno derivado do fato de que ambas as inserções de vocabulários em $\mathrm{R} \mathrm{e} v$ ocorrem em um contexto em que ambos estão diretamente concatenados com a raiz. Por isso, não assumimos uma análise em termos de circunfixação. (BASSANI, 2013, p. 253).

Em resumo, Bassani (2013) propõe uma estrutura estritamente binária para as formações parassintéticas, sendo o prefixo baixo na estrutura sintática. Esse prefixo ocupa a posição de um núcleo $\mathrm{R}$, que é responsável pela introdução do argumento interno.

\section{Uma proposta de derivação para as formações em des-X-ar}

Nesta seção, apresentamos a nossa proposta de derivação para os verbos em des- $X$ -ar. O desenvolvimento da análise estruturada aqui tem como objetivo capturar as propriedades empíricas do corpus de referência coletado no Dicionário Houaiss (2009) e descrito na seção 2 , além de mostrar-se adequada de um ponto de vista teórico-explicativo. Para tanto, apoiamo-nos nos pressupostos metodológicos do quadro teórico da $\mathrm{MD}$, que foi brevemente exposto na seção 4. Além disso, nossa proposta colocará em discussão aspectos centrais das diferentes linhas de análise descritas na seção anterior. 
Em relação aos verbos totalmente parassintéticos, como desbravar, descabelar, destronar, desossar, descascar, observamos que:

Há uma relação de localidade entre a raiz e o prefixo, de modo que nenhum afixo fonologicamente realizado pode intervir entre eles.

O processo de formação do verbo inclui necessariamente a presença do prefixo. Assim, na ausência do prefixo a formação é agramatical.

A presença do argumento interno é dependente da presença do prefixo.

Do ponto de vista analítico, interpretamos o fato empírico em (a) como uma evidência de que o prefixo se concatena diretamente à raiz. Por sua vez, a observação em (b) é interpretada a partir da ideia de que o prefixo está abaixo do primeiro núcleo que categoriza a raiz. Assim, no momento de entrada do prefixo, a estrutura não pode ser realizada na língua simplesmente porque ainda não foi categorizada pelo verbalizador. Tais elementos corroboram a proposta desenvolvida em Bassani (2013) na análise de verbos parassintéticos.

Já a observação em (c) é explicitada em nossa análise pela ideia de que o categorizador verbal é um núcleo introdutor de argumento interno. Nesse sentido, como o prefixo é anterior à presença do categorizador, no momento em que o argumento interno é licenciado, o prefixo já se anexou à estrutura sintática. Tal fato distancia nossa proposta de Bassani (2013), que assume ser o próprio prefixo, como uma realização fonológica do núcleo $\mathrm{R}$, o responsável por introduzir o argumento interno na estrutura.

Na nossa proposta, então, o próprio núcleo verbalizador é responsável por licenciar argumentos, o que é corroborado pelo fato de que muitos verbos não prefixados apresentam argumentos internos, sem a necessidade de que se assuma um núcleo relacionador zero na estrutura sintática. A estrutura resultante das opções analíticas delineadas acima pode ser vista a seguir:

(18)

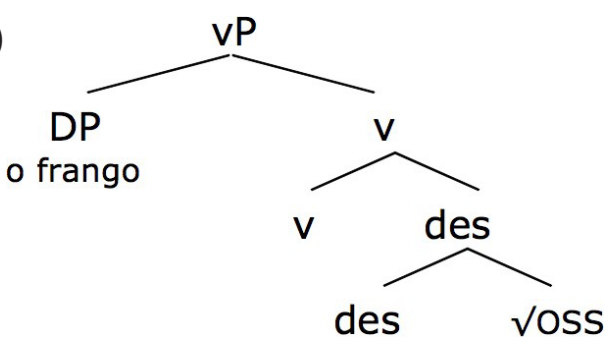

É interessante ressaltar que assumimos que a derivação ocorre a partir de uma raiz acategorial. Tal proposta nos distancia do raciocínio desenvolvido em Villalva (1994), 
uma vez que, para a autora, na ausência de um afixo derivacional verbalizador realizado, deve haver um processo de conversão do radical. Esse processo é responsável por alterar uma categoria prévia e acontece anteriormente à entrada do prefixo.

A alternativa aqui desenvolvida parece ser mais adequada, tanto do ponto de vista empírico quanto do ponto de vista teórico. Empiricamente, não é difícil encontrar casos em que a mesma raiz aparece com diferentes categorias, o que parece apontar para o estatuto acategorial da raiz. Desse modo, a categoria parece ser produto das relações que a raiz estabelece com os outros elementos do contexto sintático e não uma propriedade intrinsecamente a ela relacionada. Dessa mesma forma, do ponto de vista teórico, não é claro na proposta de Villalva (1994) qual seria exatamente a operação lexical responsável por converter uma categoria em outra, antes de qualquer elemento ser anexado à estrutura. Essa operação de conversão não se faz necessária na proposta aqui desenvolvida.

Nesse mesmo sentido, alguns dados parecem apontar para uma derivação diretamente a partir da raiz, tal como em desvirtuar e deslocar, por exemplo. Se tais derivações fossem fruto de um processo de recategorização, como sugere Villalva (1994), seriam esperadas formações como em * desvirtualar (a partir de virtual) ou * deslocalar (a partir de local).

Por outro lado, no que diz respeito às formações parcialmente parassintéticas (ex.: desacorrentar, desapontar, desconcertar, desvalorizar, desandar) e não parassintéticas (ex.: desbloquear, desabafar, descontar, desencontrar, desjejuar), foram detectadas as seguintes propriedades:

(a) A relação de localidade entre a raiz e o prefixo pode ser fonologicamente interrompida através de um afixo realizado entre eles.

(b) O processo de formação do verbo não inclui necessariamente a presença do prefixo. Assim, na ausência do prefixo a formação é gramatical.

(c) A presença do argumento interno é independente da presença do prefixo.

Na implementação da análise, propomos que o fato empírico em (a) seja uma evidência de que, nessas formações, o prefixo não está diretamente concatenado à raiz, diferentemente da estrutura em (18). Nesse sentido, será necessário propor duas posições sintáticas para alojar o elemento prefixal em cada um dos casos.

Mais especificamente, então, nas formações parcialmente e não parassintéticas, o prefixo é mais alto na estrutura sintática. A proposta de duas posições sintáticas distintas para o prefixo distancia nossa análise da hipótese desenvolvida tanto em Medeiros (2010) quanto em Medeiros (2016), nas quais há uma única posição para a realização do formador des- . 
Por outro lado, o fato empírico em (b) nos leva à ideia de que o núcleo verbal categorizador é necessariamente mais baixo do que o prefixo, de modo que a formação do verbo é, então, independente da presença do prefixo. Uma vez que estamos assumindo que o próprio processo de verbalização é responsável pelo licenciamento do argumento interno, então, é uma consequência lógica da proposta que a entrada desse elemento seja, nas formações em questão, completamente independente da presença ou da ausência do prefixo.

Dessa forma, quando o prefixo é inserido na estrutura, tanto o processo de categorização quanto a entrada do argumento interno já aconteceram. A estrutura que resulta desse raciocínio pode ser vista abaixo:

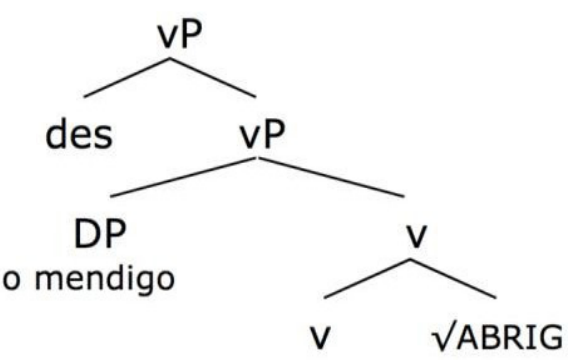

A estrutura delineada em (19) tem alguns aspectos em comum com a estrutura em (18). Mais especificamente, o estatuto acategorial das raízes é assumido nas duas estruturas. Nesse sentido, a raiz precisa ser categorizada para que uma estrutura sintaticamente legível seja gerada. Esse fato tem sido representado, dentro do modelo, através da postulação da existência de núcleos funcionais especializados $(n, v, a)$, responsáveis por fornecer categoria à estrutura a que eles se anexam. Tais núcleos fazem parte do conjunto de elementos funcionais da língua e estão sujeitos ao processo de Inserção de Vocabulário. Embick e Noyer (2007) sistematizam a necessidade de concatenação entre raiz e núcleo categorizador através da Hipótese de Categorização (Categorization Assumption) delineada abaixo:

Hipótese de categorização: as raízes não podem aparecer se não forem categorizadas; as raízCies são categorizadas através da sua combinação com um núcleo funcional definidor de categoria. (EMBICK e NOYER, 2007 , p. 5, tradução nossa ${ }^{8}$ )

A hipótese de categorização é satisfeita nas duas estruturas pela entrada do catego-

\footnotetext{
${ }^{8}$ Categorization Assumption: Roots cannot appear without being categorized; Roots are categorized by combining with category-defining functional heads. (EMBICK; NOYER, 2004:5)
} 
rizador verbal. No entanto, a posição sintática desse categorizador é diferente em uma e outra estrutura, o que é capaz de derivar as diferentes propriedades empíricas destacas na descrição do fenômeno.

Assim, as estruturas em (18) e (19) têm em comum o fato de que o argumento interno é inserido pelo núcleo categorizador, que não só tem a função de fornecer categoria, mas também está ligado à estrutura de argumento das formações em que participa. Tal fato difere a nossa análise de Medeiros (2016), que propõe a existência de estrutura argumental abaixo de uma projeção de raiz.

Por fim, é interessante ressaltar que a proposta desenvolvida nesta seção diverge tanto da análise conhecida na literatura como parassíntese, quanto da linha analítica conhecida como circunfixação. Dessa forma, a visão de parassíntese comumente assumida como um processo caracterizado por uma afixação simultânea de um prefixo e um sufixo a uma base não se aplica à nossa análise. Assim, na nossa proposta, não há a necessidade de qualquer afixação simultânea, já que as estruturas são devidamente hierarquizadas através de uma ramificação estritamente binária. Por outro lado, a circunfixação comumente caracterizada pela anexação de um morfema descontínuo a uma base também não se aplica à nossa análise. Dessa forma, na nossa proposta, des- e -ar são unidades independentes uma da outra, o que se mostra como um efetivo ganho teórico e empírico, já que não carrega os problemas atrelados à noção de circunfixação. $\mathrm{O}$ processo analisado em questão não se adequa, portanto, a nenhuma das nomenclaturas propostas.

De acordo com a proposta desenvolvida neste artigo, as formações totalmente parassintéticas em des- $X$-ar podem ser reinterpretadas como formações em que a entrada do prefixo ocorre na estrutura sintática anteriormente à categorização, dessa forma, o prefixo, de alguma maneira, faz parte do próprio processo de verbalização e a sua ausência gerará a agramaticalidade na formação. As formações não parassintéticas e parcialmente parassintéticas podem, por outro lado, ser redefinidas como formações nas quais o prefixo se realiza fonologicamente acima do núcleo categorizador verbal, o que licencia uma formação gramatical, mesmo na ausência desse elemento.

\section{Considerações sobre os verbos em $d e s-X$-ar}

Este trabalho revisita, a partir de uma abordagem sintática da formação de palavras, as formações verbais em des- $X$-ar do português brasileiro. De maneira geral, as propostas desenvolvidas ao longo deste trabalho estão sistematizadas abaixo:

(a) As formações em des- $X$-ar distribuem-se em três diferentes padrões: formações totalmente parassintéticas; parcialmente parassintéticas e não parassintéticas. 
(b) Verificamos uma forte interação entre morfologia e sintaxe ao comparar-se as (im)possibilidades de ausência do prefixo no licenciamento do argumento interno nos padrões propostos.

(c) Estruturas estritamente binárias são capazes de dar conta das formações verbais em des-X-ar.

(d) Nos verbos parcialmente parassintéticos o prefixo é estruturalmente alto, anexando-se depois que o processo de categorização da raiz, bem como a entrada do argumento interno, já aconteceu.

(e) Nos verbos totalmente parassintéticos o prefixo é estruturalmente baixo, anexando-se diretamente à raiz. Isso faz com que a ausência de des-nos parcialmente parassintéticos seja opcional, enquanto para os totalmente parassintéticos a ausência do prefixo não seja licenciada, tornando a formação agramatical.

(f) O núcleo categorizador, além de fornecer categoria à estrutura a que se anexa, também é responsável pela introdução do argumento interno.

\section{Referências}

ALCÂNTARA, Cíntia da Costa. As classesformais do português e sua constituição: um estudo à luz da teoria da morfologia distribuída. Tese (Doutorado) - Pontifícia Universidade Católica do Rio Grande do Sul, Porto Alegre, 2003.

ANDERSON, Stephen. A-Morphous Morphology. Cambridge: Cambridge University Press, 1992.

ARAD, Maya. Locality Constraints on the Interpretation of Roots: the Case of Hebrew Denominal Verbs. Natural Language and Linguistics Theory, v. 21, p. 737-778, 2003.

ARONOFF, M. Word Formation in Generative Grammar. Cambridge: MIT Press, 1976.

BASÍLIO, Margarida. Estruturas lexicais do português. Petrópolis: Vozes, 1980.

. O Conceito de Vocábulo na obra de Mattoso Câmara. São Paulo: D.E.L.T.A., 20. ESPECIAL, 2004, p. 71-84.

. Formação e Classes de Palavras no Português do Brasil. 2ed. São Paulo: Editora Contexto, 2009.

BASSANI, I. S.; MEDEIROS, A. B.; SCHER, A. P. Verbos denominais com prefixo desno português do Brasil. In: LIMA-SALLES, H. M. M.; NAVES, R.R. Estudos formais das gramáticas das línguas naturais, Goiânia: Cânone, 2011, p. 123-137.

BASSANI, Indaiá Santana de. Uma abordagem localista para morfologia e estrutura argumental dos verbos complexos (parassintéticos) do português brasileiro. Tese. Universidade de São Paulo. São Paulo, 2013.

BASSETO, B. F. A parassíntese: teoria e prática. Essen: Verlag Die Blaue Eule, 1993. 
BORER, Hagit. Taking Form: Structuring Sense. v. II. Oxford: Oxford University Press, 2013a.

. The syntactic domain of Content, in Becker, M., J. Grinstead, and J. Rothman (eds.) Generative Linguistics and Acquisition: Studies in Honor of Nina Hyams. Amsterdam: John Benjamins, p. 205-48, 2013 b.

. Derived nominal and the domain of Content. Lingua, vol.141, p. 71-96, 2014.

CAMARA Jr., Joaquim Mattoso. História e Estrutura da Língua Portuguesa. Rio de Janeiro: Padrão, 1975.

CHOMSKY, Noam. Remarks on nominalization. In: JACOBS, R.; ROSENBAUM, P. Readings in English transformational grammar. Waltham, Mass: Ginn \& Company, 1970, p. 184-221.

CORREIA, Margarita; ALMEIDA, Gladis Maria de Barcellos. Neologia em português. São Paulo: Parábola, 2012.

EMBICK, David; ROLF, Noyer. Distributed Morphology and the Syntax/Morphology Interface. In: RAMCHAND, Gilliam; REISS, Charles (eds). The Oxford handbook of Linguistics Interfaces. Oxford: Oxford University Press, p. 298-324, 2007.

HALLE, Morris; MARANTZ, Alec. Distributed Morphology and the pieces of inflection. In: HALE, K.; KEYSER, S. J. (eds.). The view from Building, v. 20, Cambridge, MA: MIT Press, p. 111-176, 1993.

HALLE, M. Distributed morphology: Impoverishment and fission. MIT Working Papers in Linguistics, p. 425-449, 1997.

HARRIS, James W. 1999. Nasal Depalatalization No, Morphological Well-formedness Sí: The Structure of Spanish Word Classes. In: Papers on Morphology and Syntax: Cycle One, edited by Karlos Arregi, Benjamin Bruening, Cornella Krause, and Vivian Lin, 4782. Cambridge, MA: MIT.

HENRIQUES, Claudio Cezar. Morfologia: Estudos lexicais em perspectiva sincrônica. Rio de Janeiro: Elsevier, 2007.

HOUAISS, A.; VILLAR, M.S. Dicionário Houaiss da Língua Portuguesa. Rio de Janeiro: Objetiva (CD-ROM), 2009.

KEHDI, Valter. Formação de palavras em português. São Paulo: Ática, 2005.

LIEBER, Rochelle. On the organization of the lexicon. Ph.D. Dissertation. Massachusetts Institute of Technology, 1980.

. Deconstructing morphology. Chicago: University of Chicago Press, 1992.

LOPES, Carlos Alberto Gonçalves. Lições de morfologia da língua portuguesa. Jacobina Tipô-carimbos, 2003.

MARANTZ, Alec. No Escape from Syntax: Don't try Morphological Analysis in the privacy of your own Lexicon. In: DIMITRIADIS, Alexis; SIEGEL, Laura; SUREK- 
CLARK, Clarissa; WILLIAMS, Alexander. Proceedings of the 21st Penn Linguistics Colloquium. Philadelphia: UPenn Working Papers in Linguistics, p. 201-225, 1997. . Words and Things. Manuscrito. NYU, 2001. . Phases and words. Manuscrito. NYU, 2007. - Locality Domains for Contextual Allomorphy across the Interfaces. In: MATUSHANSKY, O.; MARANTZ, A. (Orgs.) Distributed Morphology Today: Morphemes for Morris Halle. Cambridge Mass: MIT Press, p. 95-116, 2013.

MEDEIROS, Alessandro Boechat de. Para uma abordagem sintático-semântica do prefixo des-. Revista da ABRALIN, v. 9, p. 95-121, 2010.

. Prefixos, recursividade e a estrutura do sintagma verbal. Revista do GEL, São Paulo, v. 13, n. 1, p. 56-86, 2016.

OLTRA-MASSUET, Isabel. On the notion of theme vowel: a new approach to Catalan verbal morphology. Dissertação (Mestrado em Linguística) - Massachusetts Institute of Technology, MIT, Cambridge, 1999.

PEREIRA, Rui Abel. Condições estruturais da formação de verbos em português. In: RIO-TORTO, G. Verbos e Nomes em Português. Coimbra: Almedina, 2004, p. 91-127.

- Morfologia, Sintaxe e Semântica dos Verbos Heterocategoriais. In: RIOTORTO, G. Verbos e Nomes em Português. Coimbra: Almedina, 2004, p. 17-89.

SAID ALI, M. Gramática Histórica da Língua Portuguesa. São Paulo: Edições Melhoramentos, 1966.

SIDDIQUI, D. Syntax within the word: economy, allomorphy, and argument selection in Distributed Morphology. [Linguistik Aktuell/Linguistics Today 138]. Amsterdam: John Benjamins, 2009.

SILVA, Maria Cecília Pérez de Souza \& KOCH, Ingedore Grunfeld Villaça. Linguística Aplicada ao Português: Morfologia. São Paulo: Cortez, 2005.

SILVA, M. C.; MIOTO, C. Considerações sobre a prefixação. São Paulo: ReVEL, v. 7, n. $12,2009$.

VILLALVA, Alina. Configurações não-binárias em morfologia. 1994.

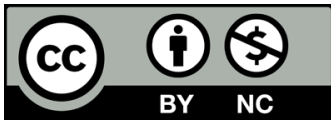

Data de submissão: $31 / 10 / 2017$

Data de aceite: $27 / 12 / 2017$ 